\title{
Diazo Preparation Via Dehydrogenation of Hydrazones with “Activated” DMSO
}

\author{
Muhammad I. Javed and Matthias Brewer
}

The University of Vermont, Department of Chemistry, 82 University Place, Burlington VT 05405

\section{Experimental}

Caution! Diazo compounds are known to be explosive and ground glass is thought to catalyze the explosive decomposition of diazomethane. Although we had no explosions while working with these compounds, suitable safety precautions were taken and all manipulations were conducted behind safety shields.

\section{I) General experimental information:}

All reactions were carried out under an atmosphere of argon using flame-dried glassware. A Büchi rotary evaporator equipped with a water condenser and attached to a Welch Model 2026 self-cleaning dry vacuum system was used to concentrate in vacuo. Samples were further dried under reduced pressure on a high vacuum line.

Tetrahydrofuran (THF), dichloromethane $\left(\mathrm{CH}_{2} \mathrm{Cl}_{2}\right)$, and diethyl ether $\left(\mathrm{Et}_{2} \mathrm{O}\right)$ were dried via a Glass Contour solvent dispensing system. ${ }^{1}$ Triethyl amine was dried over $\mathrm{CaH}_{2}$ and subsequently distilled under argon and stored in a septum sealed bottle over solid $\mathrm{KOH}$. Oxalyl chloride was freshly distilled before use. Extra dry DMSO stored over molecular sieves was purchased from Acros Organics and used as received. Benzil monohydrazone was purchased from Avocado Research Chemicals and was used as received. Benzophenone hydrazone was purchased from Alfa Aesar and purified by crystallization from ethanol before use. All other hydrazones were prepared as described previously. ${ }^{2}$ All other commercial reagents were purchased from Acros Organics or VWR International.

Reactions were cooled to $-78{ }^{\circ} \mathrm{C}$ via dry ice-acetone baths. Flash column chromatography was performed using Merck grade 60 silica gel (230-400 mesh) and TLC analysis was carried out using Merck 60F-254 silica on glass plates. Visualization of TLC plates was achieved using ultraviolet light, polyphosphomolybdic acid and cerium sulfate in $\mathrm{EtOH}$ with $\mathrm{H}_{2} \mathrm{SO}_{4}$, ceric ammonium molybdate, or iodine.

${ }^{1} \mathrm{H}$ and ${ }^{13} \mathrm{C}$ NMR spectra were recorded on a Bruker ARX 500 or a Varian Unity Inova 500 spectrometer in $\mathrm{CDCl}_{3}$ at ambient temperature unless otherwise noted. ${ }^{1} \mathrm{H}$ chemical shifts in $\mathrm{CDCl}_{3}$ were reported in ppm ( $\delta$ units $)$ downfield from tetramethylsilane. Solvent peaks were used as internal references for all ${ }^{13} \mathrm{C} N M R$. Mass spectra were recorded on a LCT Premier (Waters) operated in positive ion electrospray mode by John Greaves at the University of California-Irvine.

II) General experimental procedure for the synthesis of diazos as solutions in THF:

Oxalyl chloride $(2.62 \mathrm{mmol}, 1.05 \mathrm{eq})$ was added in a dropwise manner to a stirred solution of DMSO $(2.75 \mathrm{mmol}, 1.1 \mathrm{eq})$ in THF $(18 \mathrm{~mL})$ at $-55{ }^{\circ} \mathrm{C}$ under a nitrogen atmosphere. The reaction was maintained at $-55^{\circ} \mathrm{C}$ until gas evolution ceased $(\sim 20 \mathrm{~min})$ at which point the reaction was cooled further to $-78{ }^{\circ} \mathrm{C}$. A mixture of $\mathrm{Et}_{3} \mathrm{~N}(5.25 \mathrm{mmol}$, $2.1 \mathrm{eq})$ and hydrazone $(2.50 \mathrm{mmol}, 1 \mathrm{eq})$ in THF $(6 \mathrm{~mL})$ was added in a dropwise manner over a period of 5-7 min to the activated DMSO solution behind a blast shield. An 
immediate color change and a concomitant formation of a white precipitate were noted. The flask that had contained the hydrazone was rinsed with additional THF $(1 \mathrm{~mL})$, which was also transferred to the reaction mixture. The intensely colored solution [deep red/purple (benzophenone hydrazone); deep orange (anthraldehyde hydrazone); bright yellow (benzil monohydrazone); peach (benzaldehyde hydrazone), purple (acetophenone hydrazone); yellow (cyclohexanone hydrazone)] was covered with aluminum foil to prevent photochemical decomposition of the diazo. The reaction mixture was maintained at $-78{ }^{\circ} \mathrm{C}$ for $\sim 1 \mathrm{~h}$ and was then vacuum filtered under an atmosphere of nitrogen through a medium porosity sintered glass funnel (diameter $=30 \mathrm{~mm}$ disc) into a round bottom flask cooled at $-78{ }^{\circ} \mathrm{C}$. The reaction flask and white precipitate were rinsed with an additional $5 \mathrm{~mL}$ THF to provide the diazo product as a clear, intensely colored solution.

III) Synthesis and isolation of stable diazo compounds:

Dipheyldiazomethane: Oxalyl chloride $(0.93 \mathrm{~mL}, 10.70 \mathrm{mmol})$ was added in a dropwise (1) manner to a stirred solution of DMSO $(0.80 \mathrm{~mL}, 11.21 \mathrm{mmol})$ in THF $(100$ $\mathrm{mL})$ at $-55{ }^{\circ} \mathrm{C}$ under a nitrogen atmosphere. The reaction was maintained at $-55^{\circ} \mathrm{C}$ until gas evolution ceased $(\sim 20 \mathrm{~min})$ at which point the reaction was cooled further to $-78{ }^{\circ} \mathrm{C}$. A solution of benzophenone hydrazone $(2.00 \mathrm{~g}, 10.19 \mathrm{mmol})$ and $\mathrm{Et}_{3} \mathrm{~N}(3.01 \mathrm{~mL}, 21.40 \mathrm{mmol})$ in THF $(10 \mathrm{~mL})$ was added in a dropwise manner to provide a deep red solution containing a white precipitate. The flask that had contained the hydrazone mixture was rinsed with additional THF $(1 \mathrm{~mL})$, which was transferred to the reaction mixture. The reaction mixture was maintained at $-78^{\circ} \mathrm{C}$ for $1 \mathrm{~h}$ and was then vacuum filtered under an atmosphere of nitrogen through a medium porosity sintered glass funnel into a round bottom flask. The reaction flask and white precipitate were rinsed with an additional $40 \mathrm{~mL}$ THF to provide a clear deep red solution. The solvent was removed in vacuo to provide nearly pure diphenyldiazomethane ${ }^{3}(1.95 \mathrm{~g}, 10.14$ mmol, $99 \%$ yield) as a thick red oil that solidified on cooling. Trace impurities could be removed by low temperature crystallization from pentane $(5 \mathrm{~mL})$ to provide deep red crystals (mp: $29-30{ }^{\circ} \mathrm{C}$ ).

Diazodiphenylethanone: Oxalyl chloride $(0.13 \mathrm{~mL}, 1.53 \mathrm{mmol})$ was added in a dropwise

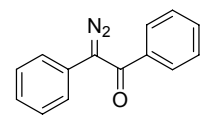
manner to a stirred solution of DMSO $(0.15 \mathrm{~mL}, 2.04 \mathrm{mmol})$ in THF (7 $\mathrm{mL})$ at $-55^{\circ} \mathrm{C}$ under a nitrogen atmosphere. The reaction was maintained at $-55^{\circ} \mathrm{C}$ until gas evolution ceased $(\sim 20 \mathrm{~min})$ at which point the reaction was cooled further to $-78{ }^{\circ} \mathrm{C}$. A solution of benzil monohydrazone $(0.23 \mathrm{~g}, 1.02 \mathrm{mmol})$ and $\mathrm{Et}_{3} \mathrm{~N}(0.41 \mathrm{~mL}, 3.07 \mathrm{mmol})$ in THF $(3 \mathrm{~mL})$ was added in a dropwise manner to provide a bright yellow solution containing a white precipitate. The reaction mixture was maintained at $-78{ }^{\circ} \mathrm{C}$ for $1 \mathrm{~h}$ and was then vacuum filtered under an atmosphere of nitrogen through a medium porosity sintered glass funnel. The filtrate was diluted with diethyl ether $(100 \mathrm{~mL})$ and washed with water $(200 \mathrm{~mL})$, sat. aq. $\mathrm{NaHCO}_{3}(2 \mathrm{X} 100 \mathrm{~mL})$, brine $(100 \mathrm{~mL})$, dried over $\mathrm{Na}_{2} \mathrm{SO}_{4}$, and concentrated in vacuo to provide the title compound $(0.22 \mathrm{~g}, 0.99 \mathrm{mmol})$ as a yellow solid in $97 \%$ yield with characterization data identical to published values. ${ }^{4}$ 
IV) Quantification of Diazo Yield:

(i) Ester Formation:

DMSO $(0.79 \mathrm{~mL}, 1.12 \mathrm{mmol})$ in $\mathrm{CH}_{2} \mathrm{Cl}_{2}(1 \mathrm{~mL})$ was added in a dropwise manner to a solution of oxalyl chloride $(0.09 \mathrm{~mL}, 1.02 \mathrm{mmol})$ in $\mathrm{Et}_{2} \mathrm{O}(5 \mathrm{~mL})$ at $-55{ }^{\circ} \mathrm{C}$ under a nitrogen atmosphere. The reaction was maintained at $-55^{\circ} \mathrm{C}$ until gas evolution ceased ( $\sim 20 \mathrm{~min})$ at which point the reaction was cooled further to $-78{ }^{\circ} \mathrm{C}$. A solution of hydrazone $(1.02 \mathrm{mmol})$ and $\mathrm{Et}_{3} \mathrm{~N}(0.29 \mathrm{~mL}, 2.06 \mathrm{mmol})$ in $\mathrm{Et}_{2} \mathrm{O}(4 \mathrm{~mL})$ was added in a dropwise manner to provide an intensely colored solution containing a white precipitate. The reaction mixture was maintained at $-78{ }^{\circ} \mathrm{C}$ for $1 \mathrm{~h}$, pentane $(10 \mathrm{~mL})$ was added and the mixture was vacuum filtered through a medium porosity sintered glass funnel to provide a clear, intensely colored solution. Benzoic acid (10 mmol, 4 eq) was immediately added in one portion to the cold diazo solution and the reaction was allowed to warm to room temperature during which time gas evolution was observed. The progress of the reaction was clearly indicated by the disappearance of the characteristic diazo color. Upon completion of the reaction the mixture was diluted with $\mathrm{Et}_{2} \mathrm{O}(75 \mathrm{~mL})$, washed with saturated aq. $\mathrm{NaHCO}_{3}(2 \times 50 \mathrm{~mL})$, brine $(50 \mathrm{~mL})$, dried with $\mathrm{Na}_{2} \mathrm{SO}_{4}$, and concentrated in vacuo to give the desired ester which could be further purified by flash column chromatography (pentane and EtOAc 90:10); Diphenylmethyl benzoate (88\% yield; rf: 0.58$),{ }^{5}$ benzyl benzoate (75\% yield; rf: 0.50$),{ }^{6} 1$-phenylethyl benzoate $(61 \%$ yield; rf: 0.52$),{ }^{6}$ and cyclohexyl benzoate ( $4 \%$ yield; rf: 0.44$)^{7}$ had characterization data identical to published values.

9-anthracenylmethyl benzoate (90\% yield; pentane and EtOAc 90:10 rf: 0.36); ${ }^{1} \mathrm{H}$ NMR $\left(500 \mathrm{MHz}, \mathrm{CDCl}_{3}\right) \delta 8.49(\mathrm{~s}, 1 \mathrm{H}), 8.42(\mathrm{~d}, \mathrm{~J}=8.5 \mathrm{~Hz}), 8.02(\mathrm{~d}, 2 \mathrm{H}, \mathrm{J}$ = 8.4), $7.99(\mathrm{dd}, 2 \mathrm{H}, \mathrm{J}=8.3,1.3 \mathrm{~Hz}), 7.56(\mathrm{td}, 2 \mathrm{H}, \mathrm{J}=7.8,1.3 \mathrm{~Hz}), 7.43-$ $7.50(\mathrm{~m}, 3 \mathrm{H}), 7.32(\mathrm{t}, \mathrm{J}=8.1 \mathrm{~Hz}) ;{ }^{13} \mathrm{C} \mathrm{NMR}\left(125 \mathrm{MHz}, \mathrm{CDCl}_{3}\right) \delta 167.1$, $133.3(1 \mathrm{H}), \quad 131.7, \quad 131.5, \quad 130.4, \quad 130.1(1 \mathrm{H}), \quad 129.6(1 \mathrm{H}), \quad 129.4(1 \mathrm{H})$, 128.6(1H), 127.0(1H), 126.6, 125.5(1H), 124.4(1H), 59.7(2H); HRMS (CI) calcd for $\left[\mathrm{C}_{22} \mathrm{H}_{16} \mathrm{O}_{2} \mathrm{Na}\right]^{+}$: 335.1048 ; found: 335.1047 .

(ii) Procedure for the Acid Catalyzed Decomposition of Diazo Compound:

The procedure used to quantitate the gas evolved during acid catalyzed diazo decomposition was based on the methods described by Holton, McGuiness and Shechter. ${ }^{8}$

General description of gas evolution measurement:

Due to the instability of many diazo compounds (which tend to decompose thermally or photochemically and can be explosive at high concentrations) it is often not prudent to accurately measure the yields of diazo compounds as isolated products. It is well established that diazo compounds undergo acid catalyzed decomposition to liberate nitrogen gas, which in turn can be measured to determine the quantity of diazo present. ${ }^{9,10}$ The apparatus we used to quantitate the nitrogen gas evolved during the acid catalyzed decomposition of diazos is shown in Figure 1. A general description of this apparatus and its use follows: 
The diazo compound is cooled to $0{ }^{\circ} \mathrm{C}$ in round bottom flask $\mathbf{A}$ and acid is added via addition funnel $\mathbf{B}$. The evolved nitrogen causes expansion through cold trap $\mathbf{C}$ (maintained at $-78^{\circ} \mathrm{C}$ to trap any solvent vapors) and the gas warms to room temperature (as measured by thermometer $\mathbf{E}$ ) as it passes through ballast $\mathbf{D}$ (filled with Ascarite II to trap any acid vapors; 8-20 mesh; cat\# C049H40, Thomas Scientific, NJ, USA). The volume of gas evolved is read in burette $\mathbf{G}$ after equilibrating the system's internal pressure to atmospheric external pressure by adjusting the height of leveling bulb $\mathbf{H}$. Knowing the temperature, the external atmospheric pressure (as measured on a barometer and corrected for water vapor pressure), and the volume of nitrogen evolved (minus a correction for a reproducible volume increase observed for blanks) allows one to calculate the number of moles of nitrogen gas liberated from the reaction using the ideal gas equation (Eq. 1). This in turn allows one to calculate the yield of the diazo compound using (Eq. 2).

Moles of Diazo Present $=$ Moles of $\mathrm{N}_{2}$ Gas Evolved $=\left(\mathrm{P}_{\text {corrected }} \times \mathrm{V}_{\text {corrected }}\right) \div(\mathrm{R} \times \mathrm{T})$

(Eq. 1)

Where:

$\mathrm{P}_{\text {corrected }}=\mathrm{P}_{\text {observed }}-\mathrm{P}_{\text {water vapor }}(\mathrm{atm})\left[\mathrm{P}_{\text {observed }}=\right.$ external barometric pressure; $\mathrm{P}_{\text {water vapor }}=$ vapor pressure of water at temperature $\mathrm{T}^{11}$ ]

$\mathrm{V}_{\text {corrected }}=\mathrm{V}_{\mathrm{N} 2 \text { gas evolved }}-\mathrm{V}_{\text {blank }}(\mathrm{mL})$

$\mathrm{R}=$ universal gas constant, $82.058\left(\mathrm{~mL} \mathrm{~atm} \mathrm{~mol}^{-1} \mathrm{~K}^{-1}\right)$

$\mathrm{T}=$ room temperature $(\mathrm{K})$

$\%$ Diazo Yield $=(\#$ of moles of diazo measured $\div \#$ of moles of hydrazone used $) \times 100 \quad$ (Eq. 2$)$

Detailed Experimental Procedure for establishing diazo yield based on gas evolution:

The diazo compounds were prepared as THF solutions by the general experimental procedure described above and vacuum filtered through a medium porosity sintered glass funnel under a nitrogen atmosphere into a $250 \mathrm{~mL} 2$ neck round bottom flask cooled to $-78{ }^{\circ} \mathrm{C}$ and containing an egg shaped magnetic stirring bar. The round bottom flask (A, Figure 1) was then transferred to an ice-water bath and a jacketed addition funnel (B) containing ice-water in the jacket and $20 \mathrm{~mL}$ of $30 \%$ (by wt) $\mathrm{H}_{2} \mathrm{SO}_{4}$ solution in methanol : water (1:1) in the addition funnel was connected. The apparatus used to quantitate the amount of nitrogen gas evolved $(\mathbf{C}-\mathbf{H})$ was attached to the second neck of the round bottom flask. The entire system was purged with nitrogen gas by attaching a nitrogen filled balloon via an 18 gauge needle inserted through the rubber septa at the top of the jacketed pressure equilibrating dropping funnel (B). A closed system was formed by closing 3-way stopcock $\mathbf{F}$ to the atmosphere. Approximately 100 $\mathrm{mL}$ of nitrogen gas (as measured in burette $\mathbf{G}$ ) was allowed to enter into the closed system and was then vented to the atmosphere by opening stopcock $\mathbf{F}$ and this purging process was repeated 3 additional times. At the end of the last purge cycle, the nitrogen gas filled balloon was removed and stopcock $\mathbf{F}$ was closed to the atmosphere. The system was allowed to equilibrate for 15 min while the diazo solution was rapidly stirred. Any pressure buildup during this time was released to the atmosphere through stopcock $\mathbf{F}$. The height of the pressure equalizing bulb $\mathbf{H}$ was adjusted to an initial volume reading in burette $\mathbf{G}$ of $0 \mathrm{~mL}$ ( $0 \mathrm{~mL}$ being at the top of the burette) and the $\mathrm{H}_{2} \mathrm{SO}_{4}$ solution was 
added in a continuous stream to the efficiently stirred solution of diazo. Rapid evolution of nitrogen gas occurred as the diazo color disappeared. The system is allowed to equilibrate for $15 \mathrm{~min}$ at which point the pressure equalizing bulb $\mathbf{H}$ was lowered until the water levels in bulb $\mathbf{H}$ and burette $\mathbf{G}$ coincided. The volume of the gas evolved (read on burette $\mathbf{G}$; typically $>50 \mathrm{~mL}$ ), the temperature (read from thermometer $\mathbf{E}$ ), and the barometric pressure (barometer not shown) was recorded. The yield of diazo compound was calculated using equations $\mathbf{1}$ and $\mathbf{2}$.

\section{Measurement of $\mathrm{V}_{\text {blank }}$}

The procedure described above for establishing diazo yield based on gas evolution was repeated exactly as described above with the following modification; flask A was charged with THF only, no diazo compound was present. At the end of the experiment the volume measured in burette $\mathbf{G}$ was consistently less than $1 \mathrm{~mL}$. The average volume after seven repetitions was $0.61 \mathrm{~mL}$ which was used as $\mathrm{V}_{\text {blank }}$ in the calculation of $\mathrm{V}_{\text {corrected }}$ (equation 1).

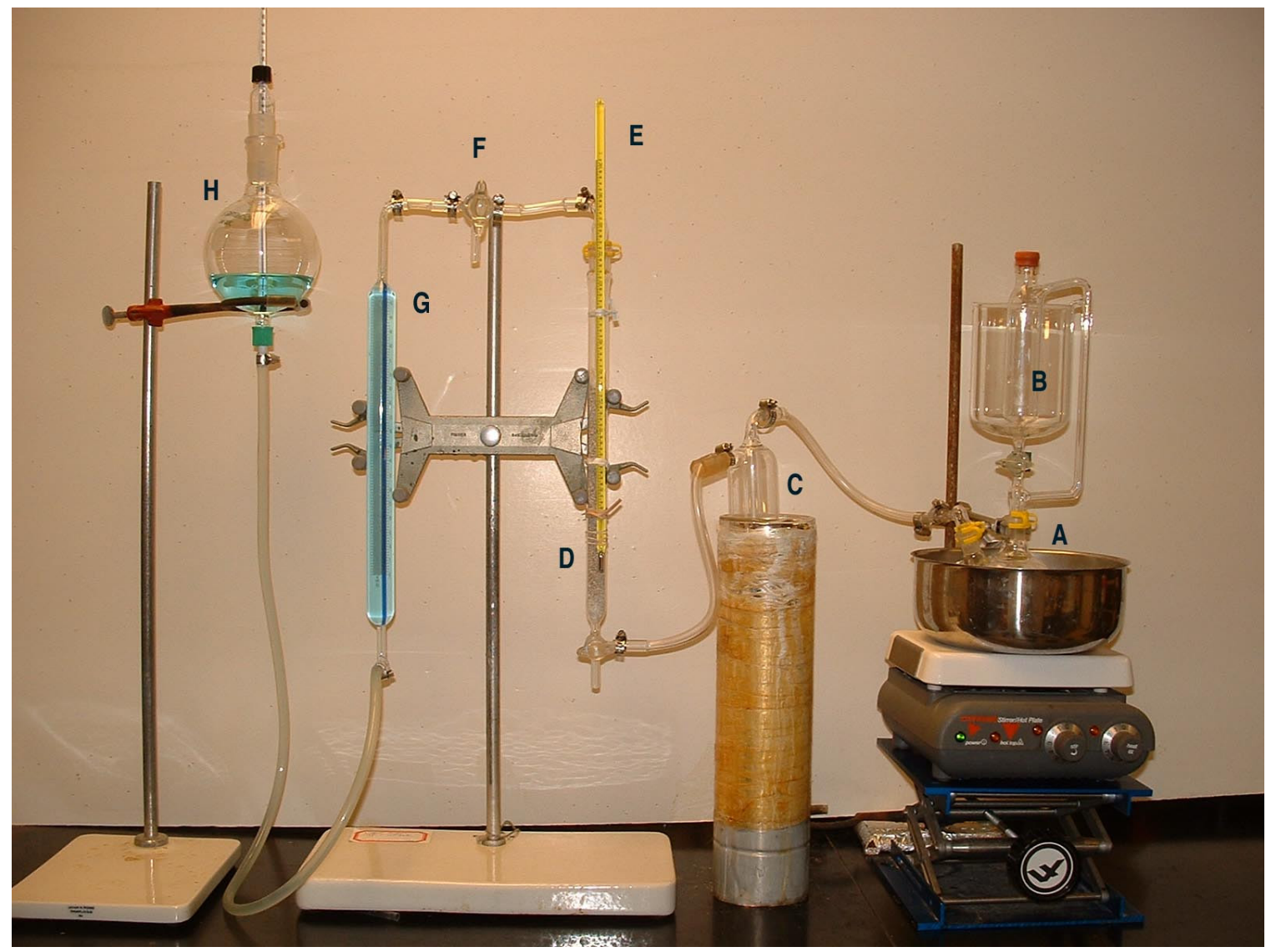

Figure 1. Apparatus used to measure volume of gas evolved from acid catalyzed diazo decomposition. 


\section{Reference:}

1. Pangborn, A. B.; Giardello, M. A.; Grubbs, R. H.; Rosen, R. K.; Timmers, F. J. Organometallics 1996, 15, 1518-1520.

2. Pross, A.; Sternhell, S. Aust. J. Chem. 1970, 23, 989-1003.

3. Smith, L. I.; Howard, K.L. Organic Syntheses, Coll. Vol. 3, 351.

4. Nicolaou, K. C.; Mathison, C. J. N.; Montagnon, T. J. Am. Chem. Soc. 2004, 126, 5192-5201.

5. Strazzolini, P.; Giumanini, A. G.; Verardo, G. Tetrahedron 1994, 50, 217-254.

6. Chen, C. T.; Munot, Y. S. J. Org. Chem. 2005, 70, 8625-8627.

7. Werner, T.; Barrett, A. G. M. J. Org. Chem. 2006, 71, 4302-4304.

8. The apparatus and procedure we used to measure nitrogen gas evolution is based on that described by: (i) Holton, T. C. "The Synthesis of Diazo Compounds by LowTemperature Oxidation of Hydrazones with Lead Tetraacetate", Ph. D Thesis, The Ohio State University, 1971, 98-102. (ii) McGuiness, M.J. "Synthesis of Diazo Compounds with Azidotris(diethylamino)phosphodium Bromide", Ph. D Thesis, The Ohio State University, 1991, 242-245. (iii) Holton, T. C.; Shechter, H. J. Org. Chem. 1995, 60, 4725. 9. Cheronis, N. D.; Ma., T.S. Organic Functional Group Analysis; Interscience Publishers New York, NY, 1964.

10. Smith, P. A. S. Derivatives of Hydrazine and Other Hydronitrogens Having N-N Bonds; The Benjamin / Cummings Publishing Co.: Reading, 1983.

11. In Handbook of Chemistry and Physics; 67th ed.; Weast, S. C., Ed.; CRC Press, Inc.: Boca Raton, 1986, p D-143. 